\title{
DISBOND GROWTH DETECTION IN COMPOSITE-COMPOSITE SINGLE-LAP JOINTS USING CHIRPED FBG SENSORS
}

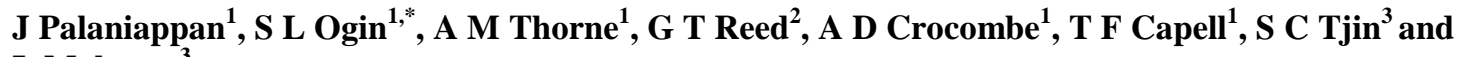 \\ L Mohanty ${ }^{3}$ \\ ${ }^{1}$ School of Engineering, University of Surrey, GU2 7XH, UK \\ ${ }^{2}$ Advanced Technology Institute, School of Electronics and Physical Sciences, University of \\ Surrey, GU2 7XH, UK \\ ${ }^{3}$ School of Electrical and Electronic Engineering, Photonics Research Centre, Nanyang \\ Technological University, Singapore \\ *E-mail: S. Ogin@surrey. ac. uk (tel : 00441483689614 ; fax : 00441483 686291)
}

\begin{abstract}
Adhesively bonded composite-composite single-lap joints, with cross-ply GFRP adherends, have been cyclically loaded to initiate disbonding at either end of the overlap length. Disbond initiation and growth have been monitored using a combination of in situ photography (the joint is transparent) and a single chirped fibre Bragg grating (CFBG) sensor embedded within one composite adherend (with the low-wavelength end of the sensor adjacent to the cut end) and not in the adhesive bondline. Sensors having the same spectral bandwidth $(20 \mathrm{~nm})$, and lengths in the range $15 \mathrm{~mm}$ to $60 \mathrm{~mm}$ have been tested. The experimental results have been modelled using a combination of finite-element analysis and commercial software for predicting FBG spectra, and the predictions are in very good agreement with the experimental results. In all cases, it has been shown that the position of the disbond front can be located using the CFBG sensors with a precision of about $2 \mathrm{~mm}$.
\end{abstract}

Keywords: A. Adhesive joints; B. Disbonding; C. Finite element analysis (FEA); D. Non-destructive testing

\section{INTRODUCTION}

Bonded composite joints, consisting of composite-composite or composite-metal joints, are used in various industries. The difficulty with any bonded construction with regard to structural integrity monitoring is, of course, that the bonded structure cannot be disassembled easily. Hence the detection of defects in a bonded joint, both immediately after fabrication and during service, remains a major concern. Various NDE (nondestructive evaluation) techniques have been suggested to monitor bonded joints based on ultrasonic, acoustic, thermal and backface strain measurements [e.g. 1-4]. Among NDE optical techniques suggested, the use of uniform fibre Bragg grating (FBG) sensors has been the most widely favoured, with a number of 
demonstrations available in the literature for monitoring bonded joints, repairs and structures [e.g. 5-11]. In addition to uniform fibre Bragg gratings, chirped fibre Bragg grating (CFBG) sensors have been investigated more recently for damage monitoring in composite materials, bonded joints and sandwich structures (e.g. [1217]), following the initial demonstration by Takeda, Okabe and colleagues [e.g. 18] that such sensors could both detect and locate damage development in composite materials. The chirped FBG sensors have a linear variation of the grating period and hence reflect a spectral band of wavelengths with roughly equal intensity. The spectral bandwidth of the reflected spectra corresponds to the physical length of the sensor and this relationship is used to find the location of damage.

In previous work $[15,16]$ it was shown that a CFBG sensor could be used to monitor disbond initiation from one end of the overlap of a composite-composite bonded joint. In the present paper, the work is extended (a) to show that disbond monitoring at both ends of the overlap is possible with a single embedded sensor, and (b) to determine the effect of using different sensor lengths.

\section{EXPERIMENTAL METHODS}

The composite adherends used in this study for the single-lap joints (SLJs) were prepared from transparent continuous E-glass fibre reinforced epoxy resin cross-ply laminates with the configuration $\left(0_{2} / 90 / 0_{6}\right)_{\mathrm{s}}$, where the thickness of each ply was $0.25 \mathrm{~mm}$ and the overall adherend thickness was $4.5 \mathrm{~mm}$. . The laminates were manufactured using a tri-component epoxy resin with the following composition by weight: 100 parts of Bisplenol A Epicholorohydrin resin 300; 60 parts of MNA hardener; 4 parts of Ancamine K61B catalyser. Liquid impregnation was used to impregnate the dry glass reinforcement and the laminates were cured at $100^{\circ}$ C for 3 hours. Adherends, $20 \mathrm{~mm}$ wide and $120 \mathrm{~mm}$ long, were cut from the panels, and bonded joints with an overlap length of $60 \mathrm{~mm}$ were manufactured using a standard aerospace adhesive consisting of a one-part epoxy-type elevated temperature cure adhesive (AV 119). The adhesive was applied to the surface of each adherend and a uniform bondline between the adherends was ensured using two $0.4 \mathrm{~mm}$ diameter wire spacers. The SLJs were cured at $120^{\circ} \mathrm{C}$ for $1 \mathrm{~h}$ in a finger-tightened, spring-loaded jig to maintain light pressure on the joint. During manufacture of the panels, optical fibres containing the CFBG sensors were embedded near the first 0/90 interface, and therefore approximately $0.5 \mathrm{~mm}$ from the adhesive bondline. The 
adherends containing the sensors were cut so that the low-wavelength end of the sensor was adjacent to the cut end of one adherend (further fabrication details can be found in previous papers $[15,16]$ ). For this work, CFBG sensors with a range of sensor lengths have been used $(15,30,45$ and $60 \mathrm{~mm})$, although all sensors had the same spectral bandwidth, having a full width at the half-maximum of the reflected spectrum of $20 \mathrm{~nm}$ (i.e. the sensors have different chirp rates). Figure 1 shows a schematic diagram of the single-lap joint and the position of the embedded CFBG sensor. The optical fibre containing the sensor was spliced to the optical arrangement which consisted of a broadband light source, coupler and optical spectrum analyser (details are provided in [14-16]). The bonded joints were subjected to fatigue loading using a computer-controlled servohydraulic fatigue machine (Instron 1341) with a peak load of $8 \mathrm{kN}$, an R-value $\left(\mathrm{R}=\sigma_{\min } / \sigma_{\max }\right)$ of 0.1 , and a sinusoidal waveform with a frequency of $3 \mathrm{~Hz}$. The cyclic loading was interrupted at increasing numbers of cycles in order (a) to record the position of the growing disbond front in the transparent lap joint using an in situ digital camera, and (b) to record the reflected spectrum of the CFBG sensor with the joint subjected to a constant load of $5 \mathrm{kN}$.

\section{RESULTS AND DISCUSSION}

\subsection{Disbond monitoring at the low-wavelength end of the CFBG sensor}

In previous work [15] using a CFBG sensor with a length of $45 \mathrm{~mm}$, it was shown that a disbond initiating adjacent to the low-wavelength end of the sensor could be detected. Figure 2 shows the reflected spectra before and after the initiation of a disbond for a CFBG sensor length of $15 \mathrm{~mm}$. It can be seen that after the disbond initiates, the low-wavelength end of the reflected spectrum moves to lower wavelengths. When the disbond initiates, a short length of adherend adjacent to the disbond is unloaded and hence relaxes, causing

the sensor spacing to relax locally, so that the low wavelength end of the spectrum moves to lower wavelengths. The dip in both spectra at about $1549 \mathrm{~nm}$ corresponds to the position of the wire spacer used to ensure a uniform adhesive bondline.

Figure 3 shows the entire $60 \mathrm{~mm}$ overlap length of the transparent GFRP-GFRP bonded joint containing the $15 \mathrm{~mm}$ CFBG sensor after 14,000,15,000,17,000 and 19,000 cycles, with the arrows indicating the position 
of the sensor in relation to the growing disbond front. Figure 4 shows reflected spectra corresponding to 14,000 and 16,000 cycles. As found in previous work on CFGB sensors with a length of $45 \mathrm{~mm}$ [15], the progression of the disbond front is indicated in the reflection spectrum by a distinct perturbation in the spectrum which moves to higher wavelengths as the disbond front grows. However, the shape of the perturbation for a $15 \mathrm{~mm}$ sensor is different to the symmetrical dip in the spectrum found for a $45 \mathrm{~mm}$ sensor; for the $15 \mathrm{~mm}$ sensor, the perturbation appears as a small rise and then fall in the reflected intensity, followed by a gentler rise (this difference in the reflected spectra for different sensor lengths is explored in Section 4.1).

\subsection{Disbond monitoring at the high-wavelength end of the CFBG sensor}

Of course, a disbond can initiate at either end of a single lap-joint and this section shows that a disbond initiating at the high wavelength end can also be monitored. Figure 5 shows the reflected spectra for a CFBG sensor which extends the full length of a $60 \mathrm{~mm}$ bonded joint, both before and after disbond initiation. Figure 5 compares a reflected spectrum before fatigue cycling (hence before any damage development) and after 25,000 fatigue cycles, by which point a disbond had initiated adjacent to the high-wavelength end of the sensor. The fatigue parameters for this experiment were the same as described earlier, and again the spectra were recorded under a load of $5 \mathrm{kN}$. In this case, there is a shift in the high wavelength end of the CFBG reflected spectrum to higher wavelengths as a consequence of disbond initiation, which can be explained as follows. For this configuration, when the SLJ disbonds at the high wavelength end, the disbond enhances the load locally in the adherend which contains the embedded sensor. The consequence is that this adherend experiences an enhanced strain, which leads locally to an increased spacing for the gratings of the CFBG sensor near the sensor end, and hence the reflected spectrum here shifts to higher wavelengths.

The propagation of the disbond with continued fatigue cycling is shown in Figure 6, and corresponding reflected spectra for 34,000, 40,000 and 51,000 cycles, taken with the fatigue loading interrupted, are shown in Figure 7. A dip in the reflected spectrum at the high-wavelength end of the spectrum (which is just discernable in Figure 6) moves to lower wavelengths as the disbond propagates (the position of the dip is indicated by arrows in Figure 7). The dip in the spectrum is due to the enhanced local strain in the adherend containing the embedded sensor as a consequence of the disbonding. The intensity of the reflected spectrum 
of a chirped grating is related to the local density of the grating period; hence, a decrease in the density of the grating period local to the disbond front (due to a local increase in the grating spacing because of the enhanced local strain in the adherend) leads to a local decrease in reflected intensity, and consequently a dip in the spectrum. The density of spacings corresponding to positions in the sensor behind the disbond front is increased, so that there is a slight increase of reflected intensity at the higher wavelengths.

\section{MODELLING AND PREDICTION OF THE REFLECTED SPECTRA}

\subsection{Effect of sensor length and chirp rate}

Earlier work using a CFBG sensor with a length of $45 \mathrm{~mm} \mathrm{[16]} \mathrm{produced} \mathrm{a} \mathrm{reflected} \mathrm{spectrum} \mathrm{which} \mathrm{showed}$ a perturbation at the position of the disbond front that was significantly more symmetrical in shape compared to the perturbation shown in Figure 4 for a $15 \mathrm{~mm}$ sensor. To investigate the effect of sensor length on the reflected spectrum in the presence of a disbond, spectra for sensors with the same spectral bandwidth of 20 $\mathrm{nm}$, but different sensor lengths $(15 \mathrm{~mm}, 30 \mathrm{~mm}, 45 \mathrm{~mm}$ and $60 \mathrm{~mm}$ ) have been predicted. For these predictions, knowledge of the strain at the position of the sensor is required. A 2D FE model of the bonded joint under a tensile load of $5 \mathrm{kN}$ was carried out using ABAQUS, for which details have been provided elsewhere [16]. The model provides the longitudinal strain (E11) corresponding to the centre line position of the optical fibre. Plane strain elements were used and, for the present work, the strain (E11) parallel to the length of the optical fibre was determined for a disbond length of $5 \mathrm{~mm}$ positioned at the lower adhesiveadherend interface (see Figure 8). It should be noted that the small perturbations in strain seen in Figure 8 when moving from the end of the adherend towards the disbond front position are not artefacts of the mesh size; they are a characteristic feature of the strain field within the adherend caused by the interaction between the strain transfer between the adherends in the vicinity of the disbond and the bending of the joint under load. The strain distribution shown in Figure 8 has been used to predict the reflected spectra using OptiGrating software [19], following the method of Okabe, Takeda and colleagues [18] which modifies the refractive index and grating period as a consequence of the strain profile in order to predict the spectrum using the OptiGrating software. The parameters used in the prediction are: uniform apodization, Poisson's ratio of 0.17 and photo-elastic coefficients $\mathrm{p}_{11}=0.121$ and $\mathrm{p}_{12}=0.27$, with an index modulation, $\Delta \mathrm{n}$, of 0.0003 . 
Figure 9 shows a comparison of the reflected spectra for each sensor length (i.e. $15 \mathrm{~mm}, 30 \mathrm{~mm}, 45 \mathrm{~mm}$ and $60 \mathrm{~mm}$ ) where it is clear that the shape of the perturbation due to a disbond differs slightly for sensors with different lengths but the same spectral bandwidth (i.e. the sensors have different chirp rates). The position of the disbond front for each prediction is indicated by a short vertical line on the spectrum and in each case the actual position of the disbond front is slightly towards the low-wavelength end of the spectrum compared to the position of the minimum of the perturbation, corresponding to a spatial distance of about $0.5 \mathrm{~mm}$ for the $15 \mathrm{~mm}$ sensor length to $1.5 \mathrm{~mm}$ for the $60 \mathrm{~mm}$ sensor length. The shapes of the predicted spectra are in good agreement with differences seen in experimental results; examples for sensor lengths of $15 \mathrm{~mm}$ and $45 \mathrm{~mm}$ are shown in Figures 4 and 10, respectively. Based on these results, Figure 11 shows a comparison of the in situ photographic measurement of disbond front position in comparison with the CFBG sensor determination of disbond front position for sensor lengths of $15 \mathrm{~mm}, 30 \mathrm{~mm}, 45 \mathrm{~mm}$ and $60 \mathrm{~mm}$. In all cases, the sensors are able to measure the disbond front position to within about $2 \mathrm{~mm}$ of the position determined from the in situ photographs.

\subsection{Prediction of reflected spectra for disbonding adjacent to the high-wavelength end of the sensor}

As shown in Section 3.2, a single CFBG sensor can also monitor a disbond growing adjacent to the highwavelength end of the sensor. Predictions of the reflected spectra for this case have been made as follows. The longitudinal strain at the position of the optical fibre sensor has been evaluated using an extension of the 2D analysis described in section 4.1., in this case for a disbond with a disbond of length $10 \mathrm{~mm}$ adjacent to the high-wavelength end of the sensor. Figure 12 shows the strain at the position of the optical fibre (a) before disbonding occurs, and (b) for a disbond of length $10 \mathrm{~mm}$ (the applied load for the FE analysis is $5 \mathrm{kN}$, as previously). In Figure 12, the distance along the joint is measured from the low-wavelength end of the CFBG sensor which is adjacent to the cut end of the adherend which contains the embedded sensor, with the disbond occurring at the other end of the bond overlap length. For the "no disbond" case, the strain in the adherend at the position of the sensor increases as load is transferred from the second adherend, increasing to a plateau region about $5 \mathrm{~mm}$ from the end of the adherend. At the other end of the overlap length, the strain in this adherend increases as the load is shed from the second adherend. It should be noted that the small 
perturbations in the strain arise, again, as a consequence of the complex strains induced by the interaction between the disbond and the bending of the asymmetric joint under load. Figure 12 also shows the E11 strain for the case of a disbond of length $10 \mathrm{~mm}$ adjacent to the high-wavelength end of the CFBG sensor and Figure 13 shows the predicted reflected spectrum; the predicted spectrum has a sharp dip at the higher wavelength end which is very similar in shape to the experimental results (see Figure 7). In Figure 13, the position of the disbond front in relation to the reflected spectrum is again indicated by a small vertical line and it can be seen that the position of the disbond front corresponds to the beginning of the dip in the reflection spectrum i.e. the position of the disbond front is not at the minimum of the perturbation but about $1.5 \mathrm{~mm}$ away, towards the low-wavelength end of the sensor. This correction has been used to locate the position of the disbond front from the CFBG spectra as the disbond front extends during fatigue cycling. Figure 14 compares the position of the disbond front obtained from the CFBG reflection spectra compared with measurements of the disbond front position obtained directly from photographs, for two specimens. There is a good correlation between these measurements, which suggests that a growing disbond adjacent to the highwavelength end of the joint can also be monitored to within about $2 \mathrm{~mm}$.

\section{CONCLUSIONS}

This paper has shown that a chirped fibre Bragg grating sensor can be used to monitor disbonding at either end of an adhesively bonded single-lap joint, with the sensor embedded within one adherend and with the low-wavelength end of the sensor at the cut end of the adherend. Disbond initiation adjacent to either the low-wavelength or high-wavelength end of the sensor is indicated by a shift in the low wavelength end of the spectrum to lower wavelengths (for disbonding adjacent to the low-wavelength end) or a shift in the high wavelength end of the spectrum to higher wavelengths (for disbonding adjacent to the high-wavelength end). Disbond propagation is shown by the movement of a perturbation in the reflected spectrum which corresponds to the progression of the disbond front: for disbonding from the low-wavelength end, the perturbation moves towards higher wavelengths, and for disbonding at the high-wavelength end, the perturbation moves to lower wavelengths. The detailed shape of the perturbation depends upon the CFBG chirp rate, but in all cases a combination of finite-element modelling and commercial FBG software enables 
the position of the disbond front to be related to the perturbation in the reflected spectrum. In general, the position of the disbond front can be located with a precision of about $2 \mathrm{~mm}$, but this is likely to depend both on the adherend materials and on the position of the sensor in relation to the disbond location.

\section{ACKNOWLEDGEMENTS}

The first author would like to thank the University of Surrey for the provision of a University Research Scholarship. 


\section{REFERENCES:}

1. Cawley P. Ultrasonic measurements for the quantitative NDE of adhesive joints - potential and challenges. Ultrasonics symposium. Proc. IEEE 1992: 767-772.

2. Lowe MJS, Challis RE, Chan CW. The transmission of Lamb waves across adhesively bonded lap joints. J. Acous. Soc. Am. 2000; 107(3):1333-1345.

3. Meola C, Bruzzone A, Giorleo L, Morace RE, Vitiello A. Application of lock-in thermography in nondestructive evaluation of adhesively-bonded aluminum joints. J. Adhesion Sci. and Tech. 2004; 18(6): 635-654.

4. Crocombe AD, Ong CY, Chan CM, Wahab MA, Ashcroft IA. Investigating fatigue damage evolution in adhesively bonded structures using backface strain measurement. J. Adhesion 2002; 78(9): 745-778.

5. Kuang KSC, Cantwell WJ. Use of conventional optical fibers and fiber Bragg gratings for damage detection in advanced composite structures: A review. Appl. Mech. Rev. 2003; 56: 493-513.

6. Merzbachery CI, Kersey AD, Friebele EJ. Fiber optic sensors in concrete structures: A Review. Smart Mater. Struct. 1996; 5(2):196-208.

7. Takeda S, Aoki Y, Ishikawa, Takeda N, Kikukawa. Structural health monitoring of composite wing structure during durability test, Compos. Struct. 2007; 79:133-139.

8. McKenzie I, Jones R, Marshall IH, Galea S. Optical fibre sensors for health monitoring of bonded repair systems. Compos. Struct. 2000; 50(4): 405-416.

9. Herszberg I, Li H C H, Dharmawan F, Mouritz AP, Nguyen M, Bayandor J. Damage assessment and monitoring of composite ship joints. Compos. Struct. 2005; 67:205-216.

10. Ussorio M, Wang H, Ogin SL, Thorne AM, Reed GT, Tjin SC, Suresh R. Modifications to FBG Spectra due to matrix cracking in a GFRP composite. Construct. Build. Mater. 2006;20(1):111-118

11. Jones R, Galea S. Health monitoring of composite repairs and joints using optical fibres. Compos. Struct. 2002; 58(3):397-403. 
12. Palaniappan J, Wang H, Ogin SL, Thorne AM, Reed GT, Tjin SC, McCartney LN. Prediction of the reflected spectra from chirped fibre Bragg gratings embedded within cracked crossply laminates. Meas. Sci. Technol. 2006; 17(6):1609-1614.

13. Takeda S, Okabe Y, Takeda N. Application of chirped FBG sensors for detection of local delamination in composite laminates. Proc. SPIE 2003; 5050: 171-178.

14. Capell T F, Palaniappan J, Ogin S L, Crocombe A D, Reed G T, Thorne A M, Mohanty L and Tjin S C. The use of an embedded chirped fibre Bragg grating sensor to monitor disbond initiation and growth in adhesively bonded composite/metal single lap joints. Submitted to J. Opt. A: Pure Appl. Opt.; Expected online publication: June 2007.

15. Palaniappan J, Wang H, Ogin SL, Thorne AM, Reed GT, Crocombe AD, Tjin SC. Structural health monitoring of bonded composite joints using embedded chirped fibre Bragg gratings. Adv. Comp. Letters 2005; 14(6):185-192.

16. Palaniappan J, Wang H, Ogin S L, Thorne A M, Reed G T, Crocombe A D, Tjin SC. Changes in the reflected spectra of embedded chirped fibre Bragg gratings used to monitor disbonding in bonded composite joints . Compos. Sci. Technol. 2007, available online.

17. Minakuchi S, Okabe Y, Takeda N. Real-time detection of debonding between honeycomb core and facesheet using a small-diameter FBG sensor embedded in adhesive layer. J. Sandwich Struct. Mater. 2007; 9: 9-33.

18. Okabe Y, Tsuji R, Takeda N. Application of chirped fiber Bragg grating sensors for identification of crack locations in composites. Compos. Part A: Appl. Sci. and Manuf. 2004; 35 (1): 59-65.

19. OptiGrating, Integrated and Fiber Optical Gratings Design Software (version 4.2), Optiwave Corporation, Canada. 


\section{Figure captions:}

Figure 1: (a) Schematic diagram of the single-lap composite-composite bonded joints with the sensor embedded in one of the adherends. (b) Edge view of the joint, showing the low-wavelength end of the CFBG sensor terminating at the end of one adherend.

Figure 2: Reflected spectra recorded using a $15 \mathrm{~mm}$ CFBG sensor under a small tensile load, both before and after disbonding. The dip in the spectrum at $1549 \mathrm{~nm}$ is due to a spacer wire. The shift in the low-wavelength end of the spectrum to lower wavelengths indicates disbond initiation.

Figure 3: Growth of a disbond in a transparent GFRP-GFRP bonded joint; the arrows indicate the CFBG sensor position relative to the disbond front position.

Figure 4: CFBG reflection spectra recorded under a load of $5 \mathrm{kN}$ after (a) 14,000 cycles, and (b) 16,000 cycles, showing the movement of the perturbation in the spectrum to higher wavelengths as the disbond grows.

Figure 5: Comparision of reflected spectra for a $60 \mathrm{~mm}$ CFBG sensor before and after disbond initiation when the disbond occurs adjacent to the high-wavelength end of the sensor.

Figure 6: Disbond growth adjacent to the high-wavelength end of a CFBG sensor with increasing fatigue cycling; the arrows indicate the CFBG sensor position relative to the disbond front position.

Figure 7: CFBG reflection spectra for a disbond which has initiated adjacent to the high wavelength end of the sensor after (a) 34000 cycles, (b) 40000 cycles, and (c) 51000 cycles. The dip in the spectrum caused by the disbond front is indicated by the arrow; the dip moves to lower wavelengths as the disbond grows with continued fatigue cycling.

Figure 8: Finite-element analysis prediction of the strain distribution at the position of the centreline of a sensor for a disbond with a length of $5 \mathrm{~mm}$ which has initiated adjacent to the low wavelength end of the sensor.

Figure 9: Predicted reflected spectra for a $5 \mathrm{~mm}$ disbond for CFBG sensor lengths of (a) $15 \mathrm{~mm}$, (b) $30 \mathrm{~mm}$, (c) $45 \mathrm{~mm}$, and (d) $60 \mathrm{~mm}$ (the spectral bandwidth is constant). The position of the disbond front for each model is indicated by the short vertical line on each spectrum. 
Figure 10: CFBG reflection spectra recorded using a $45 \mathrm{~mm}$ length CFBG sensor after disbond growth of (a) $7 \mathrm{~mm}$ (12,000 cycles) and (b) $8.5 \mathrm{~mm}$ (13,500 cycles).

Figure 11: Comparison of disbond front position measured using sensors with various lengths (15 mm, 30 $\mathrm{mm}, 45 \mathrm{~mm}$ and $60 \mathrm{~mm}$ ) with in situ photographic measurements of the disbond front in each case. Here, the disbond is growing adjacent to the low-wavelength end of the sensor. The dotted line would be the line of perfect agreement between such measurements.

Figure 12: Finite-element prediction of the strain distribution at the centreline position of the optical fibre for the cases of (a) no disbond, and (b) a disbond of $10 \mathrm{~mm}$ adjacent to the high-wavelength end of the sensor. Figure 13: The predicted reflected spectrum for a disbond of length $10 \mathrm{~mm}$ adjacent to the high-wavelength end of the sensor. The position of the disbond front is indicated by the short vertical line at about $1550 \mathrm{~nm}$. Figure 14: Comparison of the disbond front position measured using a sensor of $60 \mathrm{~mm}$ with the disbond front position measured directly from photographs. Here, the disbond is growing adjacent to the highwavelength end of the sensor. The dotted line would be the line of perfect agreement between these measurements. 
a)

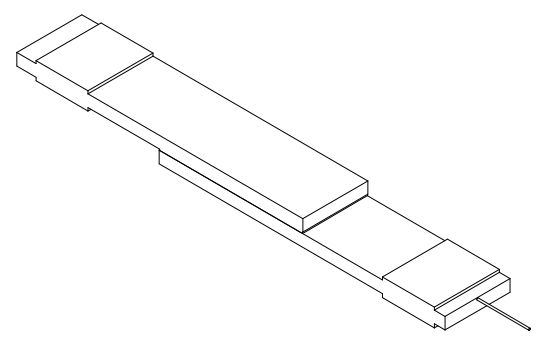

b)

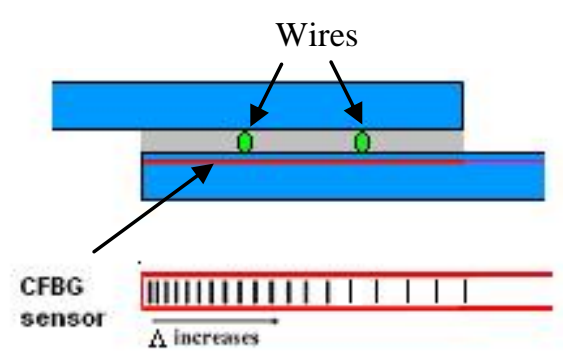

Figure 1

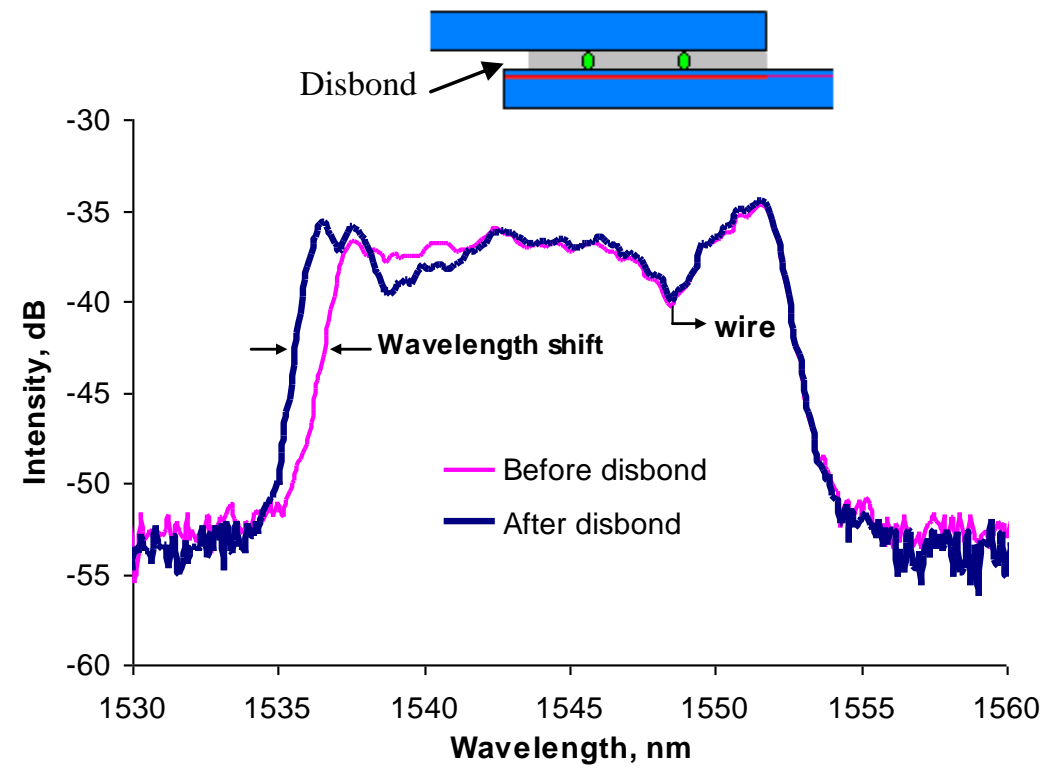

Figure 2

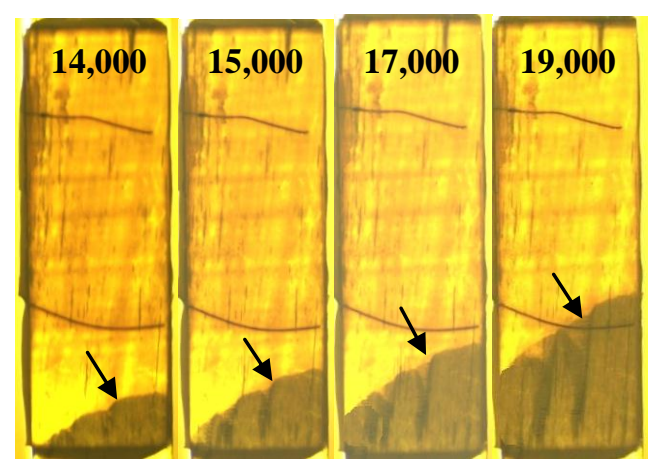

Figure 3 
a)

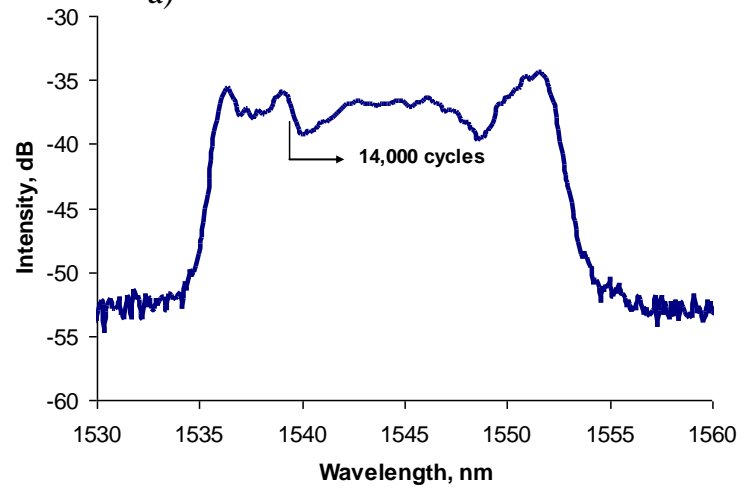

b)

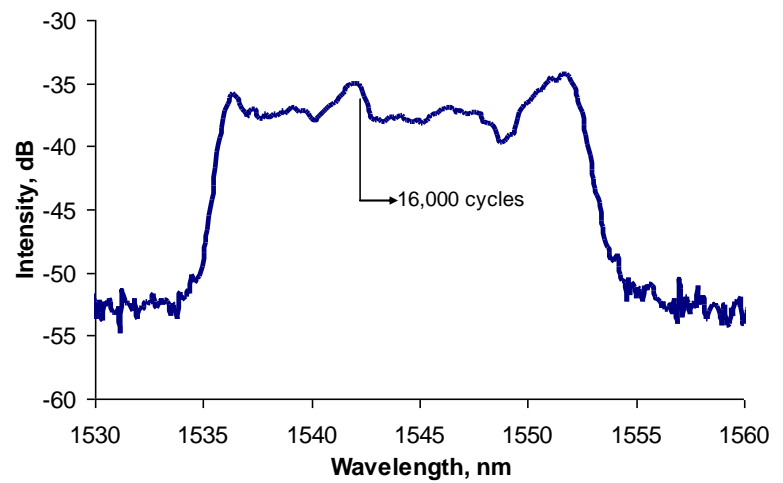

Figure 4

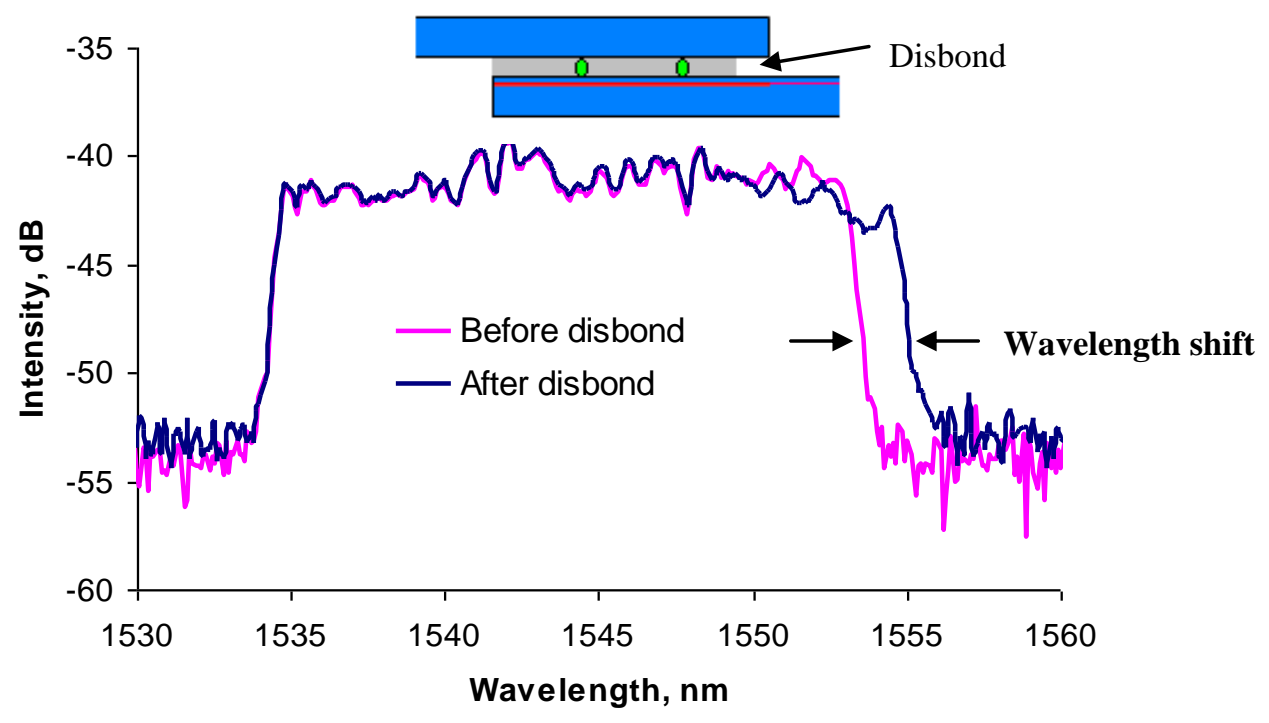

Figure 5

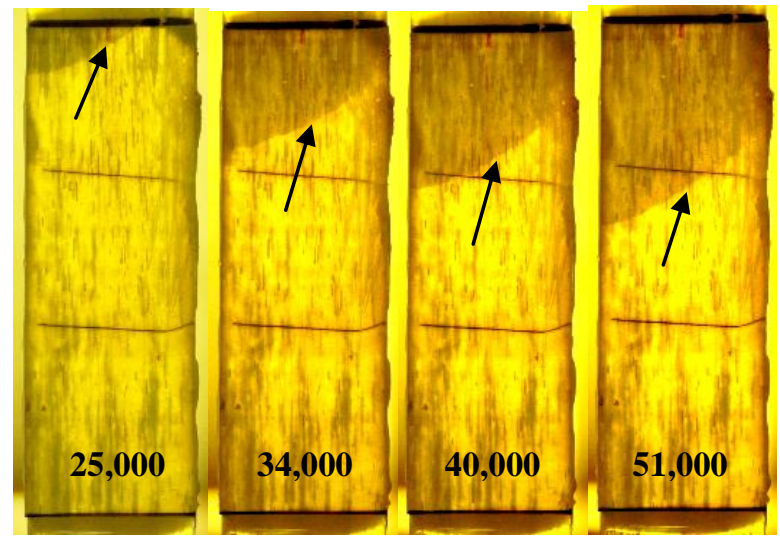

Figure 6 
a)

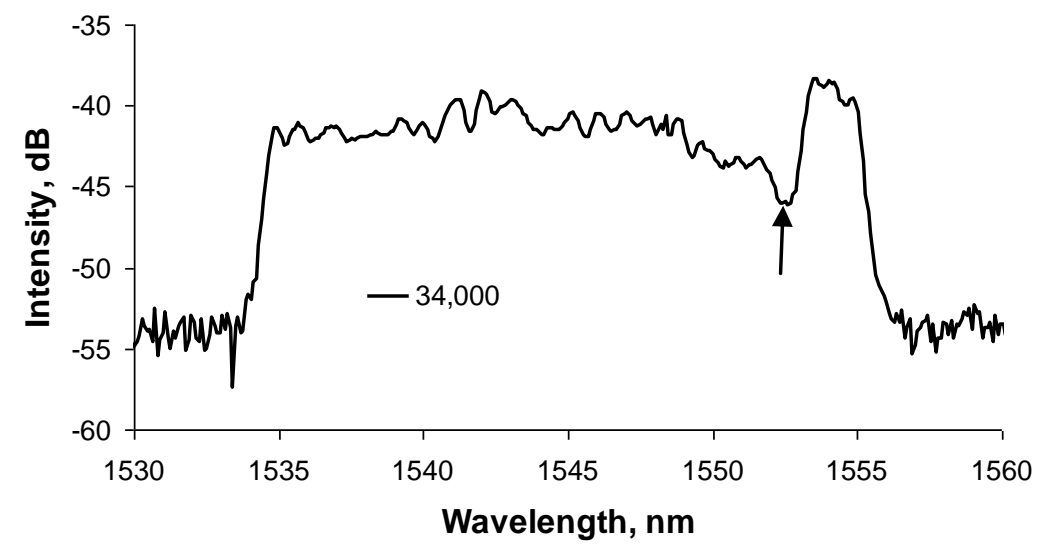

b)

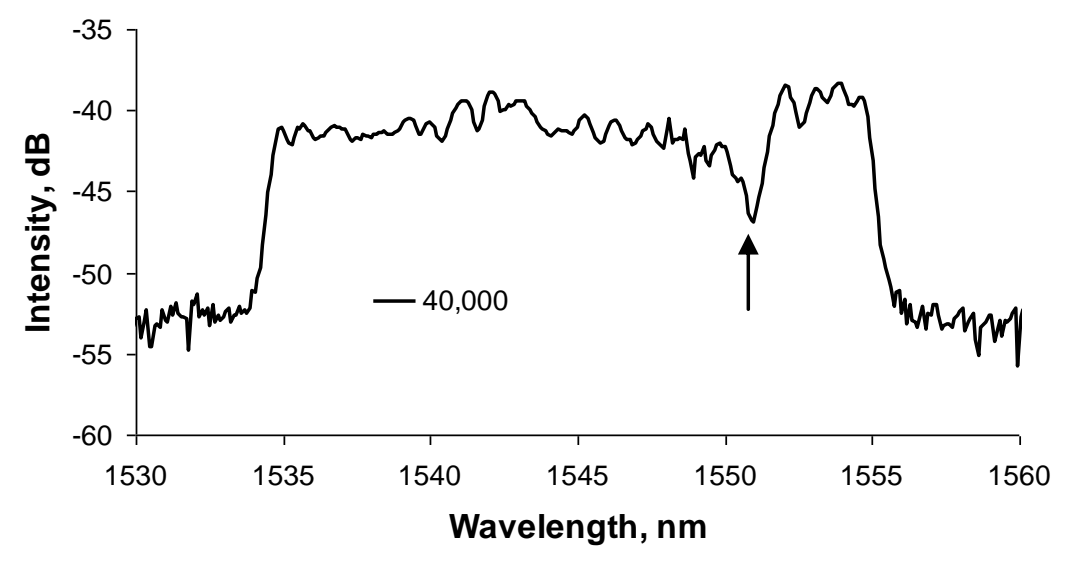

c)

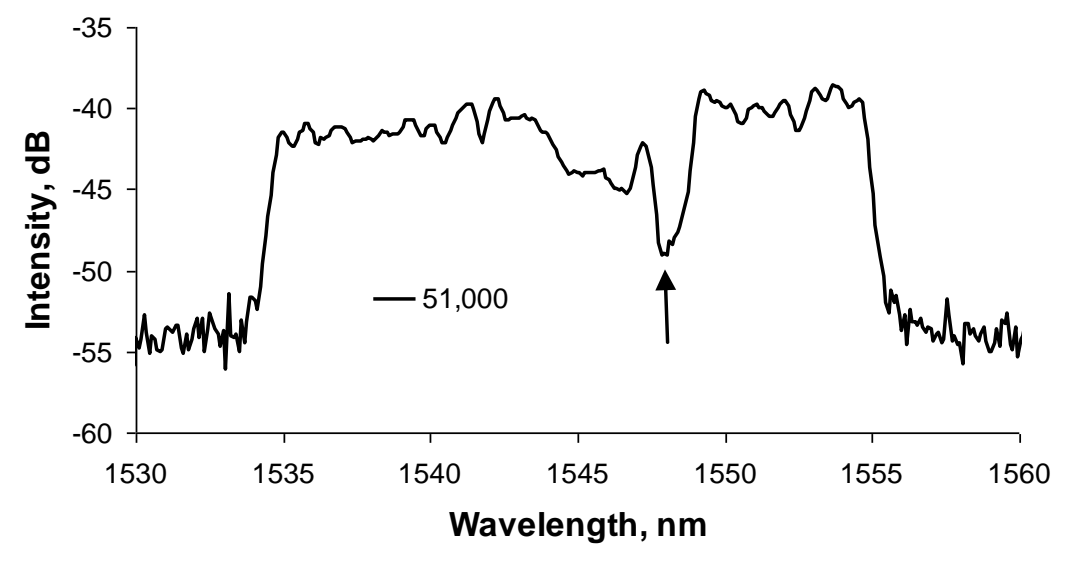

Figure 7 


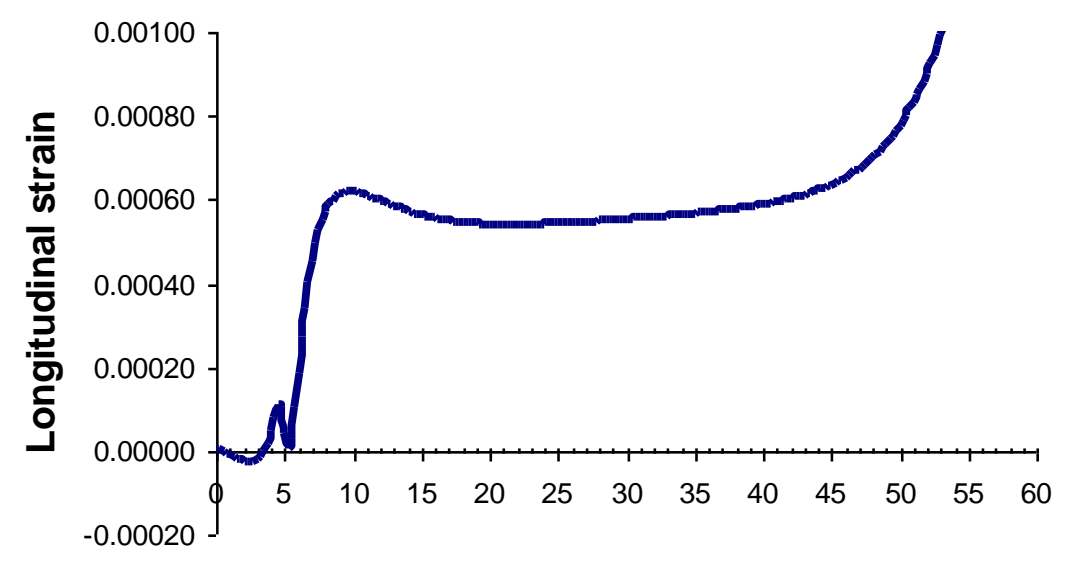

Distance along the joint, $\mathrm{mm}$

Figure 8

a)

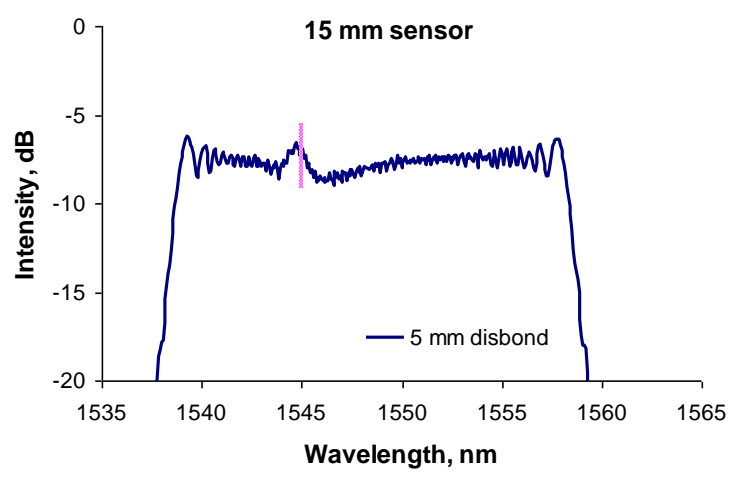

c)

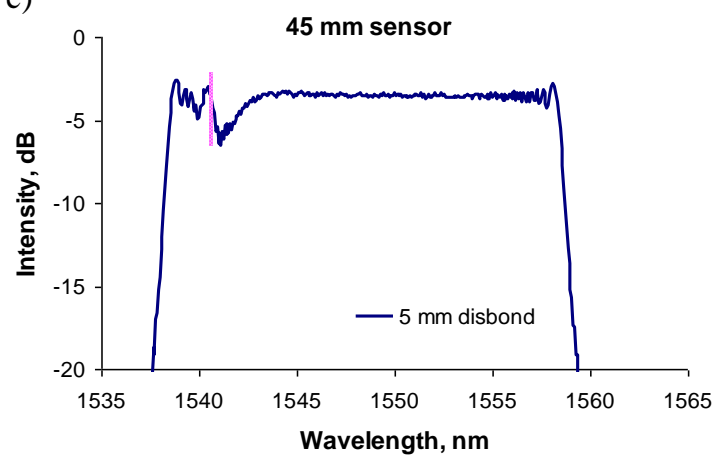

b)

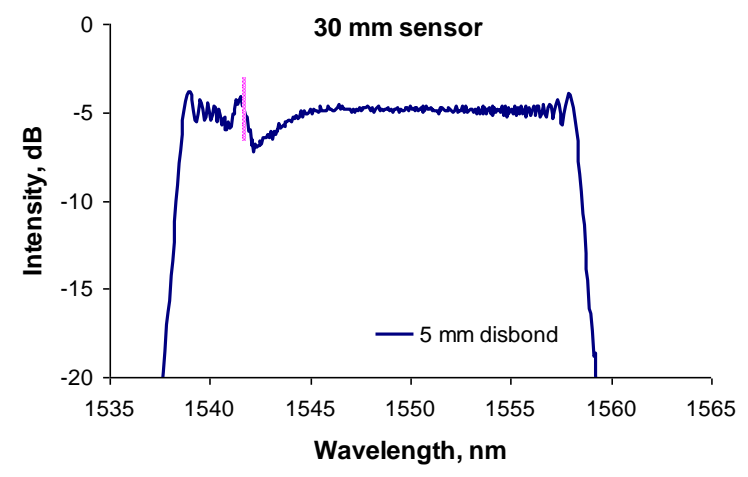

d)

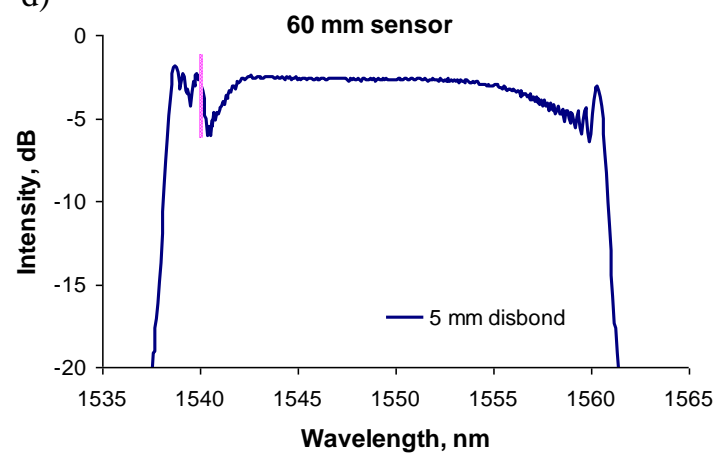

Figure 9 
a)

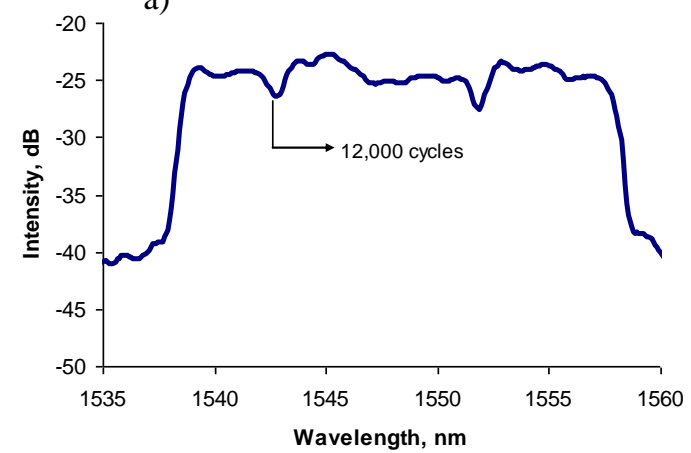

b)

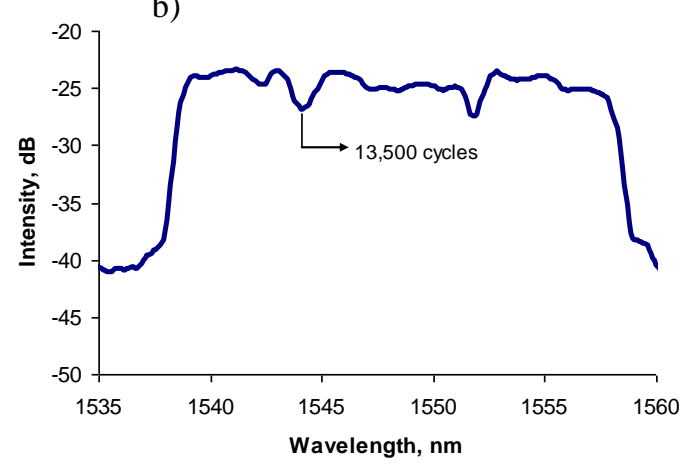

Figure 10

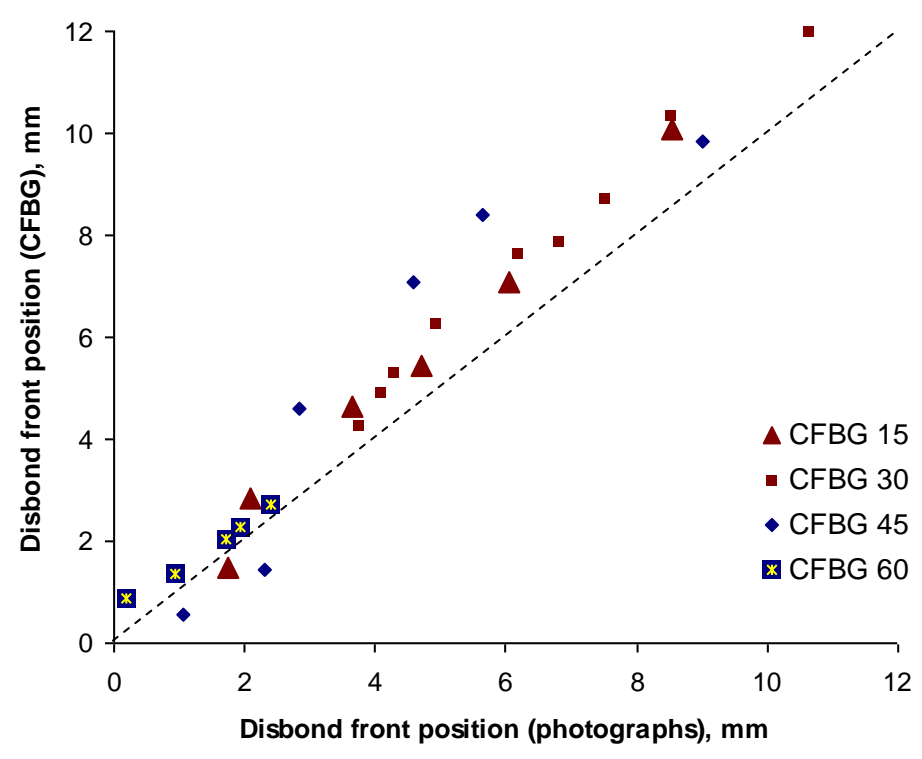

Figure 11 


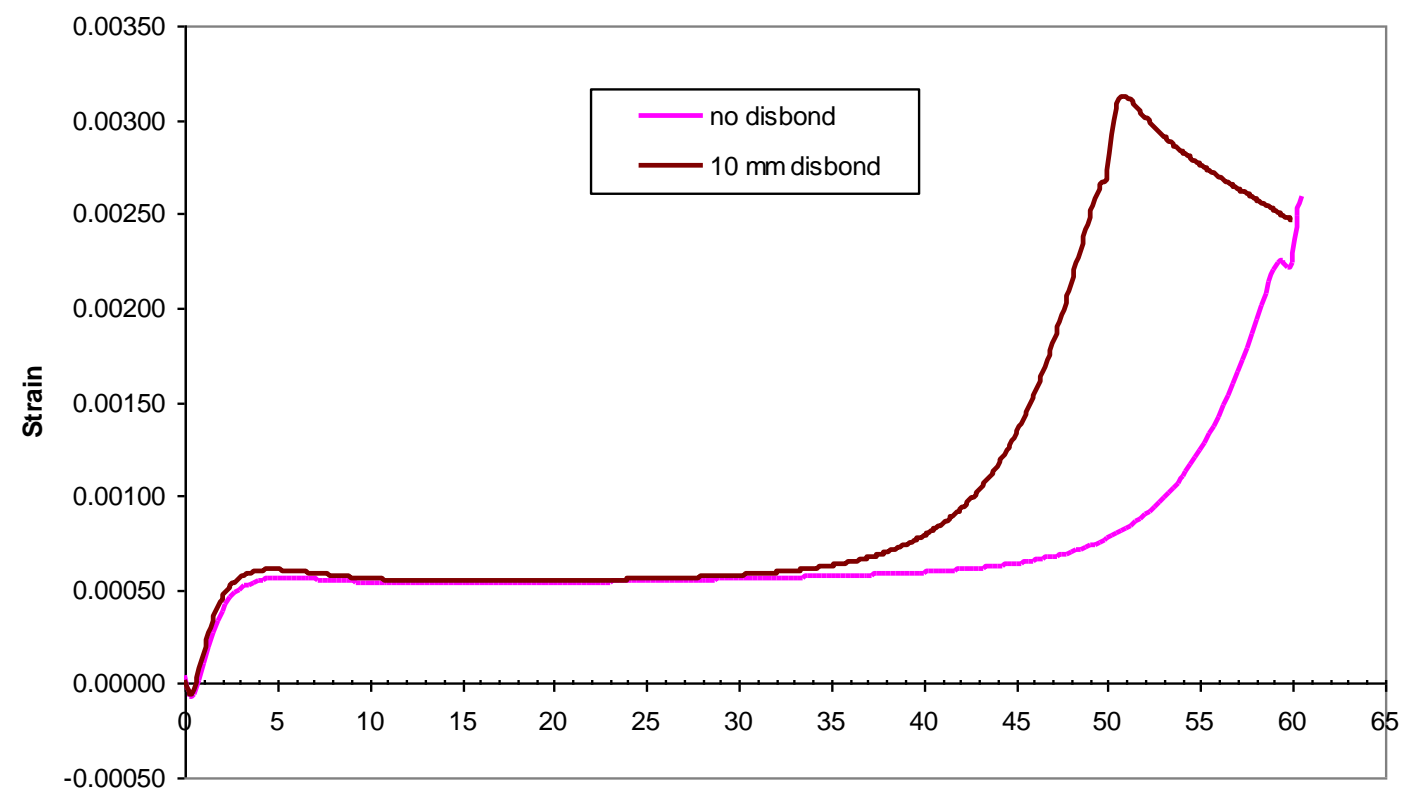

Distance along the joint, $\mathrm{m} \mathrm{m}$

Figure 12

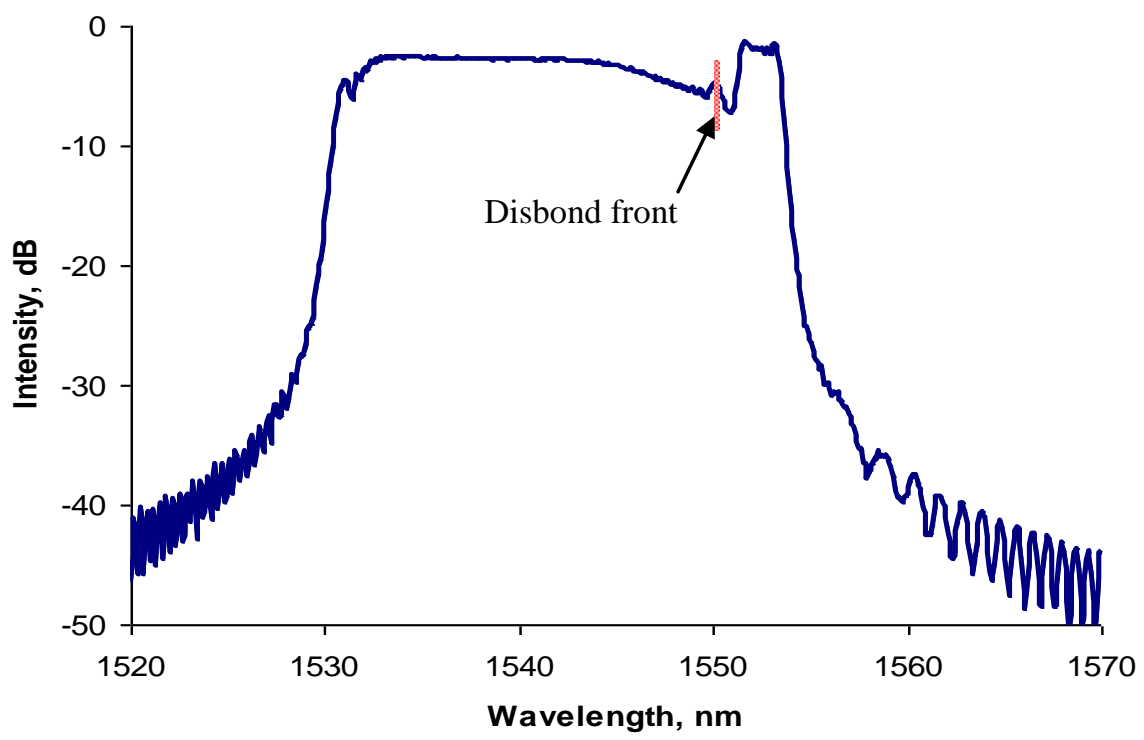

Figure 13 


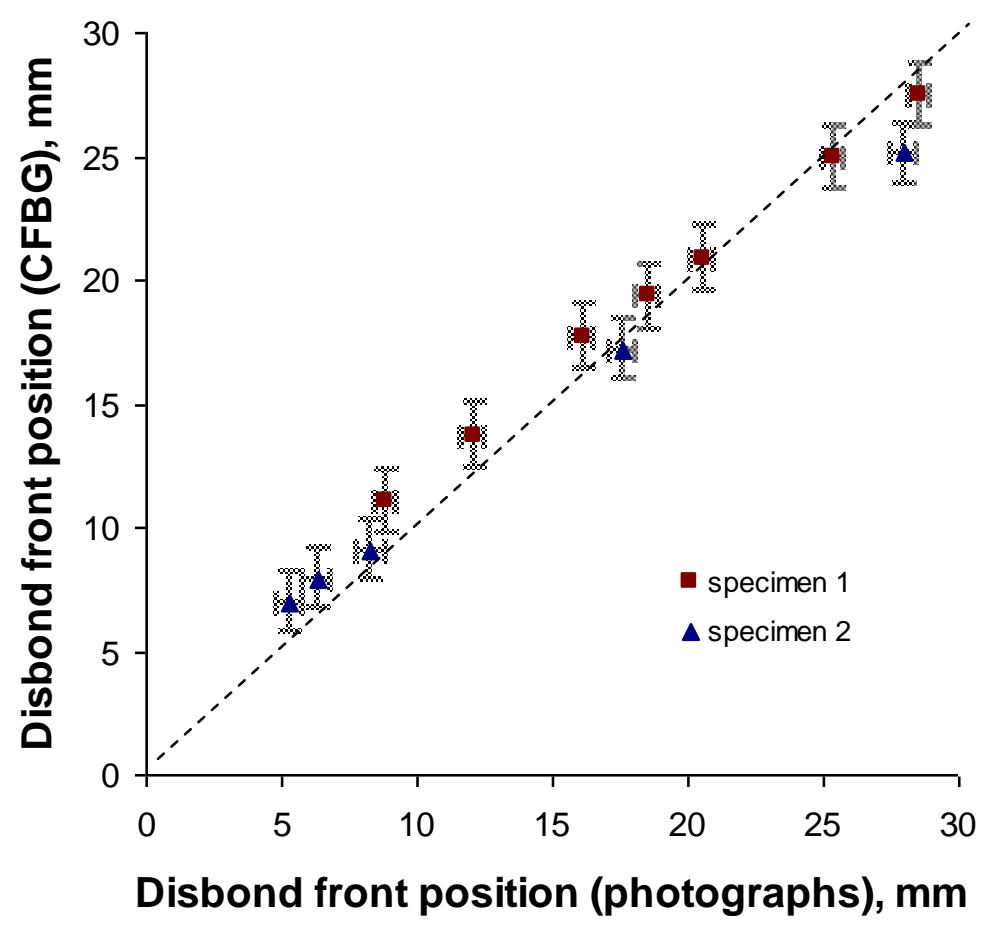

Figure 14 